TI 2011-016/1

Tinbergen Institute Discussion Paper

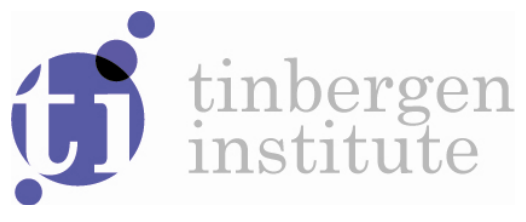

\title{
Targeted Advertising and Social Status
}

Nick Vikander

Tinbergen Institute, Erasmus University Rotterdam, and University of Edinburgh. 
Tinbergen Institute is the graduate school and research institute in economics of Erasmus University Rotterdam, the University of Amsterdam and VU University Amsterdam.

More TI discussion papers can be downloaded at http://www.tinbergen.nl

Tinbergen Institute has two locations:

Tinbergen Institute Amsterdam

Gustav Mahlerplein 117

1082 MS Amsterdam

The Netherlands

Tel.: +31(0)205251600

Tinbergen Institute Rotterdam

Burg. Oudlaan 50

3062 PA Rotterdam

The Netherlands

Tel.: +31(0)10 4088900

Fax: +31(0)104089031

Duisenberg school of finance is a collaboration of the Dutch financial sector and universities, with the ambition to support innovative research and offer top quality academic education in core areas of finance.

DSF research papers can be downloaded at: http://www.dsf.nl/

Duisenberg school of finance

Gustav Mahlerplein 117

1082 MS Amsterdam

The Netherlands

Tel.: +31(0)20 5258579 


\title{
Targeted Advertising and Social Status *
}

\author{
Nick Vikander ${ }^{\dagger}$
}

September 2010

\begin{abstract}
This paper shows how a firm can use non-targeted advertising to exploit consumers' desire for social status. A monopolist sells multiple varieties of a good to consumers who each care about what others believe about his wealth. Advertising allows consumers both to buy different varieties and to recognize them when others buy.

In equilibrium, the firm advertises each variety to those who will buy but also to all poorer consumers who will not, so that they understand what having the goods signals. If concern for status is sufficiently high, then the firm will only place a single variety on the market.
\end{abstract}

\section{Introduction}

Firms sometimes advertise high-end goods to a broad public, at a price that most people cannot afford. For instance, some firms use broad advertising for expensive new cars. Audi spent six million dollars to advertise its $\$ 118000$ R8 during the broadcast of Super Bowl XLII, reaching almost one hundred million viewers. ${ }^{1}$ Prior to the 2008 Formula 1 Canada Grand Prix, Honda showcased its $\$ 100000$ Acura NSX at a popular street festival attended by hundreds of thousands of visitors. ${ }^{2}$

Other firms use broad advertising for high-end designer clothes. The first three selections in Vogue magazine's 2008 fall fashion section were a $\$ 1200$ trenchcoat, a $\$ 5500$ watch and $\$ 600$ shoes. Handbags cost between $\$ 1700$ and $\$ 3300$. $^{3}$ Twenty out of thirty-five items from Elle's fall fashion section cost over

*I would like to thank my supervisor Maarten Janssen, Bauke Visser, Stefano Puntoni, Chaim Fershtman, Tore Ellingsen and Francisco Ruiz-Aliseda for helpful comments, as well as participants in the III Conference on the Economics of Advertising and Marketing, 2009 European Winter Meeting of the Econometric Society, ASSET 2009, and seminars in Amsterdam, Rotterdam, Stockholm and Copenhagen.

†Tinbergen Institute and Erasmus University Rotterdam, University of Edinburgh, nick.vikander@ed.ac.uk, www.tinbergen.nl/ vikander

${ }^{1}$ Brandweek, 12/15/2008, Vol.49, Issue 44 p6-6

${ }^{2}$ www.newswire.ca/en/releases/archive/June2008/03/c7902

${ }^{3}$ www.style.com/trendsshopping/theshopper/082008/ 
$\$ 700$, including a Peacock feather skirt for $\$ 2500 .{ }^{4}$ Both are mass circulation magazines, with a readership of approximately one million.

Similarly, large advertising campaigns made Nike Air Jordan shoes and the Apple iPhone household names, even though both were mainly competing with high-end brands. ${ }^{5}$

The firms sending these ads could not reasonably expect most consumers they reach to buy their products. Since advertising is costly, it would seem more efficient to target ads at specific groups of consumers who are more likely to buy. This is, after all, what firms often do. They can put great effort into selecting which of distinct audiences to reach via specialized cable television, satellite radio, and magazines (Esteban et al. 2006).

It is often possible for firms to use targeted advertising, because targeting technology continues to improve. Different households watching the same program on cable tv may simultaneously receive different ads, and someone surfing the internet will receive ads based on his personal browsing history and the exact search query typed into Google or Yahoo (Johnson 2009). What then makes the above examples of non-targeted advertising so different?

This paper puts forward an explanation for non-targeted advertising, which I define here as advertising to people who the firm does not expect to buy the good. This explanation is based on two ideas. First, consumers value social status, which depends on what other consumers believe about their wealth. Second, advertising informs consumers in two different ways. It informs consumers of the existence of goods and allows them to buy, and it also allows consumers to recognize goods when bought by others.

Recognizing essentially means that consumers can identify a good for what it is when they see it. An uninformed consumer who sees a state of the art smartphone might confuse it with a standard phone. However, a consumer who recognizes the smartphone will not make that mistake, and may infer something about the owner as someone who owns a high-end good. In this way, non-targeted advertising may encourage conspicuous consumption by helping consumers signal to each other through their purchases.

Some features of this explanation appear in previous economic analysis of social status, such as Veblen (1899), Frank (1985), Ireland (1994) and Bagwell and Bernheim (1996). Status depends on beliefs about an unobserved characteristic, such as wealth or ability, and actions only affect status to the extent that they influence beliefs. High status is associated with a high level of the characteristic, either in absolute terms or compared to some reference point. ${ }^{6}$

These papers emphasize that signaling through consumption is only possible if goods are visible to others, since only then can consumption influence beliefs. I take the approach that physical visibility is not enough. Consumers must also recognize the good to understand what having it means, creating a role for non-

\footnotetext{
${ }^{4}$ www.elle.com/fashionspotlight

${ }^{5}$ Advertising Age, 6/25/2007, Vol. 78, Issue 26, p8-8

${ }^{6}$ The mechanism would not work if people liked to conform as in Bernheim (1994), or disliked inequity as in Fehr and Schmidt (1999). But Kapferer and Bastien (2009) argues that people's desire for social stratification is the driver for luxury good sales.
} 
targeted advertising. Non-targeted advertising could only promote signaling for physically visible goods, which suggests why the above examples of advertising may be different. Cars, clothes and portable technology all tend to be highly visible.

The economics literature on advertising has largely ignored the possibility that a firm can use broad non-targeted advertising to exploit consumers' desire for social status, by allowing them to signal through their purchases. A number of authors in other fields, particularly marketing, have nonetheless alluded to this type of mechanism. Their arguments are informal, and often presented in terms of strengthening brand image. A brand is an idea, and the idea is more powerful if widely shared. More people should therefore be familiar with the brand than just the consumers who buy (Kotler and Keller 2008). It is precisely because everyone knows BMW and what it stands for, even those who will never buy a BMW car, that the brand has so much power (Kapferer 2008).

Kapferer and Bastien (2009) make a similar point in the specific context of luxury goods. They espouse what they call an anti-law of marketing, that many more people should be familiar with a luxury brand than those who are likely to buy. They contrast this approach to traditional advertising campaigns which focus only on the target market.

Miller (2009) makes a similar argument, which is clearly expressed in the following passage:

The luxury brands with the highest brand equity ... advertise in Vogue and GQ not so much to inform rich potential consumers that they exist, but to reassure rich potential consumers that poorer Vogue and GQ readers will recognize and respect these brands when they see them displayed by others. (Miller 126)

To the best of my knowledge, only two papers in the advertising literature have modeled how advertising can help consumers signal through their purchases. The first such paper is Wernerfelt (1990), which uses a very different framework than I do in this paper. I assume all consumers want to be thought of as wealthy, while Wernerfelt considers horizontal differentiation where all consumers want to reveal their type, and where firms compete in advertising to name brands. Advertising effectively allows a firm to engage in cheap talk and suggest the meaning of a brand. Consumers of different types can then coordinate on the brands which best express their identify.

In a short section, Wernerfelt also looks at vertical differentiation and argues that advertising can help sustain an equilibrium by dissipating profits in a repeated setting. The reasoning is that firms who only sell to high types may want to sell the "afterglow" of their brand's positive signal to low types in a future period, which can cause an equilibrium to break down. Allowing firms to earn positive profits could make this deviation unattractive, but that would encourage entry. He argues that an alternative way to support the equilibrium is to assume that high types will only buy from firms with the most advertising, in precisely such a way so as to make expected profits equal zero. This 
relationship between advertising and consumer beliefs seems rather ad hoc, and Wernerfelt admits the approach is not completely satisfactory.

A paper more similar to the current work is Krahmer (2006). He looks at duopoly, where firms compete in prices and advertising, and where each firm sells a single brand. Consumers are either high or low type, and they derive social status if members of "the public" believe their type is high. Members of the public can only recognize a brand if they have received an ad, so that the role of advertising is to inform the public of brand names.

Krahmer shows that equilibrium advertising tends to be higher than the social optimum, and this effect is exacerbated by competition. In monopoly, a firm overadvertises because it does not internalize how ads reduce the social status of low types who do not buy. In duopoly, an incumbent may also overadvertise to deter entry, knowing that the entrant must outadvertise him to make any sales. If two firms are active in the market, then they may also waste resources competing with each other for high types.

The basic mechanism in this paper is similar to Krahmer, but there are a number of important differences which lead to new results. First, I do not look at duopoly, but rather at a monopolist who sells multiple varieties. This different setting leads to new strategic considerations for the firm, as it must consider how its choice of advertising will affect competition between its own varieties. For instance, these considerations might make broad advertising of high-end varieties unattractive, as the firm will also want to sell varieties to lower types.

Second, a novel assumption of this paper is that advertising can simultaneously play two roles: allowing consumers to buy, and allowing consumers to signal through their purchases. Krahmer only considers the second role of advertising. In his setting, there is no need to inform consumers about the existence of brands, because consumers are already fully informed. Advertising is instead aimed at the public, whose members never buy anything but whose beliefs will determine consumers' social status.

When taken together, these two features of the model generate a trade-off in the firm's choice of advertising that has not been considered before in the literature. Broad non-targeted advertising makes varieties widely recognized, which facilitates signaling and increases willingness to pay through status effects. But it also informs individual consumers about different varieties which effectively compete with one another. This reduces the firm's ability to price discriminate, forcing it to reduce the mark-ups of varieties sold to higher types. The firm must therefore weigh its desire to exploit status effects against its desire to price discriminate. This trade-off is what drives the paper's main results.

I show that in equilibrium, the firm will advertise each variety to all consumers who buy, and also to all lower types. The model therefore predicts that poor people will receive more ads than wealthy people, but mostly for varieties they cannot afford. It also predicts that a person will be better able to distinguish between different people who are wealthier than him, than between different people who are poorer.

In particular, the firm will advertise the variety bought by the highest types 
to all consumers. This is the case even if the firm fully internalizes the negative effect this has on the status of low types, and even though status is a zero sum game. The intuition is that these ads transfer status utility between consumers who buy different varieties, but they also affect consumers' outside option. It is the latter effect which leads to higher profits, by effectively increasing the stigma associated with buying nothing.

In equilibrium, the firm will use some non-targeted advertising even for the variety bought by very low types. It does so even though these ads make low types easier to recognize and they suffer from low social status. The intuition is that advertising high-end varieties generates an unraveling effect. If the firm broadly advertises the varieties bought by all higher types, then a slightly lower type will be willing to pay to distinguish himself from those who are still lower than him.

This unraveling effect implies that the best way for the firm to exploit status effects would be to advertise each variety as broadly as possible, so to all consumers. However, doing so would reduce the firm's ability to price discriminate, because high types would prefer to buy cheaper varieties that are better deals. The firm balances these concerns by advertising each variety to some, but not all, of consumers who will not buy: to poorer consumers, but not to wealthier consumers.

The firm's desire to exploit status effects does more than influence its choice of advertising. It can also cause the firm to restrict the number of varieties it places on the market. If consumers care enough about social status, then the firm will choose to sell only a single variety. In such a situation, the firm prefers to abandon any attempt to price discriminate and instead fully exploit status effects. As noted above, this can be done by advertising each variety to all consumers. Advertising is costly, so the cheapest way to do so is to sell a single variety.

The only comparable result in the literature is Rayo (2005), who also shows a monopolist may restrict the number of varieties to exploit status effects. His mechanism is very different, however, as consumers are already informed about all goods and there is no role for advertising. Moreover, the two models predict the firm will restrict the number of varieties in opposite situations. Rayo shows that differences in consumer valuation for status must be sufficiently large, whereas here, these differences must be sufficiently small. I go into this comparison in more detail later in the analysis.

Finally, I show that non-targeted advertising makes some consumers worse off even though they enjoy high equilibrium status. If the firm can only sell a single variety, then a ban on non-targeted advertising will increase social welfare by encouraging the firm to expand output. Nonetheless, a general tax on advertising would be counterproductive. Any tax large enough to influence the firm's behavior will actually decrease social welfare.

As in Krahmer (2006), this paper shows that non-targeted, informative advertising can generate effects more often associated with persuasion. It can increase willingness to pay through status effects, and also help differentiate largely similar goods. 
Informative advertising transmits product information such as price, availability, characteristics or quality. It is direct if such credible information is directly included in the ad, as in Butters (1977), Grossman and Shapiro (1984) and Meurer and Stahl (1994). Informative advertising is indirect if it serves as a signal, for example of price (Bagwell and Ramey 1994) or quality (Milgrom and Roberts 1986, Kihlstrom and Riordan 1984).

Persuasive advertising directly affects consumer preferences or utility. Advertising may actually change consumer preferences (Dixit and Norman 1978), or enter directly into the utility function as a complement to consumption (Stigler and Becker 1977, Becker and Murphy 1993). That can reflect the idea that advertising itself creates prestige or differentiation from other goods.

Advertising in this this paper is direct and purely informative. It can be thought of as transmitting information about a variety's existence, where it can be purchased, its appearance, price, or what type of people are likely to buy it. Broad, non-targeted advertising informs people about a variety, strengthening the signal from buying and changing the social status with which it is associated. Non-targeted advertising also increases the difference in status between different varieties, by making consumers in each market segment easier to identify. Krahmer (2006) shows that this allows a firm to differentiate its brand from those of rivals, whereas I show it allows a monopolist to increase differentiation between its own varieties.

Various other explanations have been put forward for non-targeted advertising. Targeting may simply be impossible because of imperfect technology, but that is not convincing for cases where the lack of targeting is extreme.

A related reason is that perfect targeting may be too costly. Advertising costs differ, and the cheapest way to reach a target market might be to advertise in media with a broader reach. Hernandez-Garcia (1997), Esteban et al. (2001), and Esteban et al. (2006) look at this cost reason and conclude that under quite general circumstances, targeting is still optimal.

Another type of explanation relates to anchoring. A consumer may feel something is a better deal if he knows about similar but more expensive goods. That is, the utility from a particular choice may depend on the salient available alternatives (Swinkels and Samuelson 2006). Though plausible, this cannot explain why a firm would advertise to consumers who it does not expect to buy any of its products.

Finally, firms may advertise to signal product characteristics. Seemingly wasteful advertising may itself signal high quality (Nelson 1974). The mechanism here differs in that advertising does not signal anything, but instead helps consumers signal to one another. It is therefore not limited to experience goods, whose characteristics cannot be observed before purchase.

This work can also be related to models of consumption with network externalities. There, advertising can help consumers coordinate on purchases by acting as a public signal or promoting common knowledge about a product (Pastine and Pastine 2002, Chwe 2001). Here, consumers care not about who else buys a particular good, but who is believed to do so.

In a more general sense, this paper is related to the consumer research lit- 
erature on symbolic consumption. Levy (1959) argues that possessions are not only important for what they are, but also for what they mean. People may consider possessions as an extension of the self, and they can help both to develop one's self-concept and to signal it to others (Belk 1988). In particular, consumers often mention clothing, perfume and cars as means of self-expression (Aaker 1996).

In reality, ads for high-end goods may not explicitly state the price, which might seem odd if firms want to stimulate conspicuous consumption. That being said, firms often use their ads to explicitly portray what type of people are likely to buy their goods, and it is these beliefs that matter for social status. Ads often depict carefully selected lifestyle categories of consumers, so consumption choices can tell us a person's social type (Englis and Solomon 1995). For example, ads of Louis Vuitton suggest a connection with wealth and sophistication. Indeed, when visibility is high, signaling lifestyle is an important feature of many goods (Levy 1963). Firms can also suggest that certain reference groups are important by using obvious group members as spokespersons in advertisements (Kotler and Keller 2008).

The rest of the paper is organized as follows. Section 2 presents the model, and Section 3 analyzes the case of a single variety. Section 4 considers the general case where the firm can sell multiple varieties. Section 5 looks at how selling the status good affects welfare, and Section 6 concludes. All proofs are in the appendix.

\section{The Model}

A monopolist sells up to $N \geq 1$ varieties of a status good, where $N$ is exogenous. It produces each variety at constant marginal cost, normalized to zero. Consumers are initially uninformed about these varieties, which are new on the market.

Consumers differ only in their type $\theta$, which is uniformly distributed on $\left[\theta_{L}, \theta_{H}\right]$ with $\theta_{L} \geq 0$. Willingness to pay varies with type, which can be seen as a proxy for wealth. Each consumer's type is private information.

For each variety $x_{j}$, the firm sets price $p_{j}$ and decides to which consumers it will advertise. The advertising technology allows the firm to directly choose which types will receive an ad, $a_{j} \subseteq\left[\theta_{L}, \theta_{H}\right]$. The strategy of the firm, $S_{f}$, is therefore a choice of $p_{j}$ and of a set $a_{j}$ for each $x_{j}, j=1, \ldots, N$.

A consumer of type $\theta$ becomes informed about variety $x_{j}$ if he receives an ad for it, $\theta \in a_{j}$. Let $I_{\theta}$ denote the set of varieties of which type $\theta$ is informed, given the firm's advertising.

Type $\theta$ can buy one unit of a single variety, and only of a variety of which he is informed. He can also decide to buy nothing. Buying nothing can be viewed as actually buying from a known, no-name seller who does not advertise, where competition has driven price down to marginal cost (see Krahmer (2006)).

After receiving the ads, type $\theta$ makes a conjecture about what other consumers will believe about his type, conditional on his purchase. This conjecture 
is relevant because his eventual social status will depend on these beliefs. Type $\theta$ then makes a purchase.

The strategy of type $\theta$, denoted by $S_{\theta}$, is therefore a rule which, for any choice $S_{f}$ of the firm, selects an element $x_{j} \in I_{\theta}$. Let $S_{\theta}\left(S_{f}\right)$ denote the action prescribed by this strategy if the firm plays $S_{f}$. I assume that each consumer observes the firm's full strategy, $S_{f}$, before making a conjecture and taking an action. I comment more on observability of the firm's strategy and visibility of varieties at the end of this section, where I also present an alternative interpretation of this assumption.

Each consumer then forms beliefs about the type of others, based on what they have purchased. Variety $x_{j}$ is visible to type $\theta$ if and only if he himself has received an ad for it, $x_{j} \in I_{\theta}$. Type $\theta$ can distinguish between consumers who buy different varieties that are visible to him. He cannot distinguish between different consumers who buy varieties that are not visible to him, or between these consumers and those who buy nothing. The latter assumption reflects the above interpretation of a no-name seller. For example, rather than go without clothes, a cellular phone or an mp3 player, consumers will buy generic goods from little known producers. These goods may be virtually impossible for an uninformed observer to distinguish from brand-name varieties he does not recognize. He may simply not notice any difference.

Pay-offs are then realized and the game ends. I assume advertising is costly but these costs are small. The firm will therefore take costs into account when choosing its strategy, but their magnitude will not drive the results. To capture this idea, I set the explicit cost of advertising to zero in the analysis, but assume the firm uses the following lexicographic tie-breaking rule. If two different strategies both yield the highest revenue, then the firm chooses the strategy with strictly less advertising, $\sum_{j=1}^{N} m\left(a_{j}\right)$. Here, $m\left(a_{j}\right)$ denotes the measure of set $a_{j}$.

Each consumer makes the purchase which maximizes his utility, given his conjecture about what others will believe about his type. The utility of type $\theta$ consists of intrinsic utility and status utility : $U_{\theta}=(1-\lambda) U_{I}+\lambda U_{S}$. The relative weight on status is $\lambda \in(0,1)$, which is the same for all types.

If type $\theta$ buys nothing, then his intrinsic utility is zero. If he buys any variety $x_{j}$, his intrinsic utility equals his type minus the price:

$$
U_{I}=\theta-p_{j} .
$$

Higher types enjoy more intrinsic utility than lower types from any given variety. Varieties are essentially identical, in the sense of each giving the same intrinsic utility.

The status utility of type $\theta$ equals the average belief of all other consumers about his type ${ }^{7}$ :

\footnotetext{
${ }^{7}$ Another specification would be that utility depends directly on a consumer's conjectures, rather than what others actually believe. That would not affect the equilibrium outcome.
} 


$$
U_{S}=\frac{1}{\theta_{H}-\theta_{L}} \int_{\theta_{L}}^{\theta_{H}} \mu_{\theta^{\prime}}(\theta) d \theta^{\prime} .
$$

Here, $\mu_{\theta^{\prime}}(\theta)$ is the belief of type $\theta^{\prime}$ about the type of another consumer, whose true type is $\theta$.

To complete the description of the model, I impose conditions on beliefs and conjectures. Consumers form beliefs about each others' type, whenever possible, using Bayes' rule.

Consider a given candidate equilibrium and suppose the firm plays $S_{f}$, which need not be its equilibrium strategy. Let $S_{\xi}\left(S_{f}\right)$ be the action that is then prescribed by type $\xi$ 's equilibrium strategy. The beliefs of type $\theta$ about another consumer, whose true type is $\theta^{\prime}$, are specified as follows.

Suppose $\theta^{\prime}$ buys a variety that $\theta$ recognizes, $x_{j} \in I_{\theta}$. Then $\theta$ believes he is the average type who would buy this variety if all consumers played their equilibrium strategies:

$$
\mu_{\theta}\left(\theta^{\prime}\right)=\frac{\int_{\theta_{L}}^{\theta_{H}} \xi 1_{S_{\xi}\left(S_{f}\right)=x_{j}} d \xi}{\int_{\theta_{L}}^{\theta_{H}} 1_{S_{\xi}\left(S_{f}\right)=x_{j}} d \xi}=\frac{1}{q_{j}} \int_{\theta_{L}}^{\theta_{H}} \xi 1_{S_{\xi}\left(S_{f}\right)=x_{j}} d \xi .
$$

Suppose $\theta^{\prime}$ does not buy any variety that $\theta$ recognizes, $x_{j} \notin I_{\theta}$. Then $\theta$ believes he is the average type who would not buy any such variety, if all consumers played their equilibrium strategies:

$$
\mu_{\theta}\left(\theta^{\prime}\right)=\frac{\int_{\theta_{L}}^{\theta_{H}} \xi 1_{S_{\xi}\left(S_{f}\right) \notin I_{\theta}} d \xi}{\int_{\theta_{L}}^{\theta_{H}} 1_{S_{\xi}\left(S_{f}\right) \notin I_{\theta}} d \xi}=\frac{1}{\theta_{H}-\theta_{L}-\sum_{x_{j} \in I_{\theta}} q_{j}} \int_{\theta_{L}}^{\theta_{H}} \xi 1_{S_{\xi}\left(S_{f}\right) \notin I_{\theta}} d \xi .
$$

Type $\theta$ cannot use Bayes' rule if he is informed about all varieties, expects all consumers to buy some variety, but instead type $\theta^{\prime}$ buys nothing. I argue in the following section that $\theta$ should then believe the deviating consumer has the lowest possible type, $\theta_{L}$. I cannot apply standard refinements, defined in terms of best replies, since consumers do not take any actions after forming these beliefs. That being said, allowing for other out-of-equilibrium beliefs would not have an important effect on the results.

Each consumer's conjecture is correct, in the sense of reflecting the actual beliefs others will have about his type, conditional on his purchase. A consumer knows that others also observe $S_{f}$ and they form beliefs in the same way he does. He is therefore able to correctly predict their beliefs about his type. That means he can predict the status utility from any purchase, and make the choice that maximizes his utility.

There is also the issue of multiple equilibria. I take the same approach as Rayo (2005), and assume the firm can coordinate consumers on the equilibrium which gives the highest profits.

I end this section with a discussion about observability of the firm's strategy. It is important that each consumer observe $p_{j}$ and $a_{j}$ of all varieties $x_{j}$ for which 
he receives an ad. This is analogous to signaling models of advertising, where consumers need to observe the firm's advertising expenditures. If a consumer did not observe $a_{j}$ for the variety he ended up buying, the firm could profitably deviate by eliminating all non-targeted advertising for $x_{j}$, and the consumer would not notice.

I assume consumers also observe price and advertising for all other varieties, possibly hearing about these ads through word-of-mouth communication. Above all, this assumption is made for practical purposes. It amounts to assuming that the firm can commit to a mechanism (price and advertising for each variety), which is designed to be incentive compatible (each consumer purchases the desired variety). The assumption allows me to focus on the main issue at hand, the firm's trade-off between status effects and price discrimination when designing this mechanism, which is something that has not been considered before.

If the firm's strategy were not fully observable, then I would have to specify beliefs following a deviation by the firm. The question is what a consumer should believe about the ads he does not see, after himself receiving an unexpected ad. More generally, if one player notices that another player has deviated from his equilibrium strategy, but does not observe the full deviation, what should he believe this deviation actually was? Questions of this nature have been considered before, including by McAfee and Schwartz (1994) and Rey and Verg (2004), but in a very different context. They look at an upstream monopolist that supplies two retailers, where the contract with one retailer is unobservable to the other. Retailers later compete in the product market, and each must form beliefs about the contract offered to its rival, given the contract it receives. These papers consider the consequences of what they call passive and wary beliefs.

The situation here is quite different, however, and applying these concepts to the current setting is significantly more complicated. A consumer who receives an unexpected ad can observe who else has also received it, and he knows that these consumers must notice the deviation. He therefore knows that these consumers cannot retain their equilibrium beliefs. The firm can also determine which consumers notice the deviation, and the extent to which they realize that others notice, by its choice of advertising and hence by the deviation itself. Moreover, unlike the situation with two retailers, consumers care directly about others' beliefs rather than actions. It is difficult to say what consumers should believe in such circumstances.

An alternative interpretation of the assumption I make is that consumers only observe the price and advertising of varieties for which they receive an ad, but they react negatively to any deviation they notice from the firm. A basic premise of this paper is that social relationships matter. A consumer who notices a deviation should reason that the firm is trying to fool others, so that they hold beliefs about type that are incorrect. The consumer may decide not to give his business to a firm that acts in such a way. In that case, the firm will have no incentive to deviate and equilibrium results will be identical to the case with full observability. 


\section{Analysis - Single Variety}

The main focus of the paper is on multiple varieties, but it is instructive to first consider the single variety case. Assuming $N=1$ demonstrates the basic mechanism at work relating advertising to social status. It also generates a number of new insights. In terms of notation, I will omit the subscript on $x_{1}$, $p_{1}$ and $a_{1}$ since there cannot be any confusion about which variety it refers to.

If consumers did not value status, the firm would just solve the standard problem of a monopolist facing a downward sloping demand curve. It would never use non-targeted advertising, and instead advertise to exactly those consumers who it expects to buy the good. When setting its price, the firm would weigh how a marginal change in price would affect quantity sold against how it would affect the revenue on the quantity it already sells.

Note that this baseline result is very different than Esteban et al. (2001), who look at a monopolist's incentive to target using magazines with nested readership. They show that when advertising is random within each magazine's readership, the firm will sometimes advertise in magazines that reach beyond the target market. It may do so because these magazines charge a lower advertising price per reader. In contrast, I assume the cost of advertising is constant across consumers, so non-targeted advertising amounts to pure waste. They also show that a firm using targeted advertising will internalize the relationship between its price and advertising expenditures, and so charge a price above the full information monopoly level. This effect can be ignored in the current set-up because advertising costs are small.

When consumers value status, the firm also has an additional incentive to advertise compared with the baseline. It can exploit consumers' desire for status by advertising the good not only to consumers who buy, but also to all poorer consumers who do not.

Proposition 1. Let $N=1$. Then the firm always sets $a=\left[\theta_{L}, \theta_{H}\right]$. Define

$$
\lambda^{*} \equiv \frac{2 \theta_{H}-4 \theta_{L}}{3 \theta_{H}-5 \theta_{L}} .
$$

If $\lambda<\lambda^{*}$, then quantity sold and price are

$$
\begin{gathered}
q=\frac{2 \theta_{H}-\lambda\left(\theta_{H}+\theta_{L}\right)}{4(1-\lambda)}, \\
p=\frac{2 \theta_{H}-\lambda\left(\theta_{H}+\theta_{L}\right)}{4},
\end{gathered}
$$

where type $\theta$ buys if and only if

$$
\theta \geq \theta_{H}-q
$$

If instead $\lambda \geq \lambda^{*}$, then quantity sold and price are

$$
q=\theta_{H}-\theta_{L}
$$




$$
p=(1-\lambda) \theta_{L}+\lambda\left(\frac{\theta_{H}-\theta_{L}}{2}\right),
$$

and all consumers buy.

Just like in the baseline case, the firm only sells to consumers above some critical type. The main qualitative difference lies in the firm's choice of advertising. The firm now advertises to all consumers, so unless it serves the whole market this involves non-targeted advertising. The intuition is as follows.

In the absence of status effects, differences in intrinsic utility mean the firm would only sell to consumers above some critical type. For any given quantity sold, doing so maximizes the willingness to pay of the marginal consumer.

Selling above some critical type is also optimal when consumers value status, because it maximizes the difference between the expected type who buys and the expected type who does not. Consumers then have a positive status incentive to buy, since buying sends a positive signal. The signal is stronger when more consumers recognize the good, which gives the firm an incentive to advertise as broadly as possible.

The result reflects the intuition described in the introduction. The firm advertises the status good to consumers who buy it, but also to others who cannot afford it. Doing so increases the status incentive to buy, which lets the firm increase its price.

Two additional features of the result are new compared to Krahmer (2006). Both features stem from the fact that there are more than two consumer types. First, the firm's incentive to exploit status effects through advertising need not decrease if it increases quantity sold, despite the good becoming less exclusive. Second, consumers' desire for social status counteracts the monopolist's natural tendency to restrict output, so that it serves a larger part of the market. The interplay between status effects, advertising and output will play an important role when considering a tax or ban on advertising, which I discuss in Section 5.

Expanding output does not necessarily decrease the status incentive to buy, because it affects the status utility from both buying and not buying. By Proposition 1, expanding output is equivalent to decreasing the critical value of the lowest type to buy. The average type who buys is then lower, which decreases willingness to pay. However, the average type who does not buy is also lower. This has the opposite effect on willingness to pay, because buying nothing is each consumer's outside option.

The net impact of expanding output on the status incentive to buy will depend on the distribution of types. Here, where types are uniformly distributed, the two effects exactly cancel and expanding output leaves the status incentive to buy unchanged. Regardless of the critical value, the difference between the average type who buys and the average type who does not is $\left(\theta_{H}-\theta_{L}\right) / 2$. Given its equilibrium advertising, the firm prices just like a standard monopolist except there is now an extra positive constant in each consumer's willingness to pay, $\lambda\left(\theta_{H}-\theta_{L}\right) / 2$. 
This argument implies a firm may still want to use non-targeted advertising for a popular good owned by many people, and even if that advertising is costly. These ads do not have much impact on the social status of those who buy. Their purpose is to increase the stigma associated with not buying, by ensuring that those who buy nothing are recognized.

The impact of status effects on quantity sold can be seen by differentiating (6) with respect to $\lambda$. The derivative is positive, which I derive in a more general case in the following section. The reason the firm expands output when consumers place a large weight on status is that differences in willingness to pay are then small. Higher types differ from lower types only in that they enjoy more intrinsic utility from any purchase. In contrast, status is a zero sum game, where all consumers value status to the same extent. If the weight consumers place on status increases, differences between types will decrease and the firm has less incentive to restrict output.

If all consumers buy, I need to specify out-of-equilibrium beliefs about someone who deviates by buying nothing. Proposition 1 assumes such a consumer is believed to have the lowest possible type, $\theta_{L}$. This assumption is natural, in that type $\theta_{L}$ has the greatest incentive to deviate. For any given out-of-equilibrium beliefs, the difference between his utility in equilibrium and after deviating is lower than for any other type. As well, the set of out-of-equilibrium beliefs which would make the deviation profitable is larger than for any other type, in the sense of set inclusion. This argument is very much in the spirit of the D1 refinement (Cho and Kreps 1987). The refinement cannot be explicitly applied here however, because it is defined in terms of best responses, and consumers do not take actions after they form beliefs.

These out-of-equilibrium beliefs are also intuitive, in that they are the limiting beliefs of a sequence of equilibria where quantity sold tends to $\theta_{H}-\theta_{L}$. If $\lambda<\lambda^{*}$, then the firm does not serve the whole market and beliefs about those who buy nothing follow from Bayes rule. As $\lambda$ tends to $\lambda^{*}$, quantity sold increases and tends to $\theta_{H}-\theta_{L}$. Beliefs about consumers who buy nothing become more negative and tend to $\theta_{L}$. In this sense, the assumption assures that beliefs are continuous in $\lambda$.

\section{Analysis - Multiple Varieties}

I now consider the general case where the firm can sell up to $N$ varieties. In the baseline case without status effects, varieties are identical in the sense of each giving the same intrinsic utility to consumers. However, since the firm can choose which consumers to inform about which varieties, it can take advantage of this situation to price discriminate.

Without status effects, the firm would choose a critical value $\theta_{0}<\theta_{H}$, and sell to all consumers above this type. ${ }^{8}$ It would divide consumers on $\left[\theta_{0}, \theta_{H}\right]$ into $N$ segments, and sell a different variety to those in each segment. The firm

\footnotetext{
${ }^{8}$ Whether the firm would choose $\theta_{0}>\theta_{L}$ would depend on parameter values. It is more likely to be the case when both $\theta_{L}$ and $N$ are small
} 
would only advertise a variety to those consumers who would buy it, and so avoid any competition between different varieties. The price for each variety would make the lowest type to receive an ad indifferent between buying that variety and buying nothing.

Status effects now give the firm an incentive to use non-targeted advertising for all varieties.

Proposition 2. The firm sets critical values $\theta_{1} \geq \theta_{2} \geq, \ldots, \theta_{M}$, with $M \leq N$. It sells $x_{1}$ to all types $\theta \in\left[\theta_{1}, \theta_{H}\right]$ and $x_{j}$ to all types $\theta \in\left[\theta_{j+1}, \theta_{j}\right)$ for $2 \leq j \leq$ $M$. The firm sets $a_{1}=\left[\theta_{L}, \theta_{H}\right]$ and $a_{j}=\left[\theta_{L}, \theta_{j-1}\right)$ for $2 \leq j \leq M$. It sets $p_{j}$ to make type $\theta_{j}$ indifferent between buying $x_{j}$ and buying nothing.

Just as with a single variety, an important difference with the baseline case lies with the firm's choice of advertising. The firm still divides the market into segments, but now advertises each variety to all consumers who buy and to all lower types.

The driving force behind Proposition 2 is the firm's trade-off between broad advertising to exploit status effects, and more targeted advertising to better price discriminate. Before discussing this trade-off in more detail, I describe a few features of the equilibrium.

One feature of the equilibrium is that lower types receive more ads than higher types. Poor consumers are better informed, in the sense of being able to buy and recognize more varieties, but this does not necessarily leave them better off. The majority of ads they receive are for expensive varieties that they cannot afford.

Another feature is that each consumer knows more about those who are wealthier than him, than about those who are poorer. A consumer is able to recognize the different varieties bought by all higher types. He can make fine distinctions between those who are slightly wealthier, moderately wealthier and much wealthier than him, based on the different varieties these consumers buy. In contrast, he is unable to recognize varieties bought by any lower types. From his perspective, they simply form a single group of poorer consumers. It is not that he is particularly interested in recognizing wealthier consumers, but rather that the firm can profitably exploit their desire to be recognized.

Proposition 2 shows that the firm will use non-targeted advertising for the variety bought by the highest types, even if it fully internalizes the negative effect this has on all others. That is, even if all consumers buy some variety in equilibrium. ${ }^{9}$

Advertising $x_{1}$ to all consumers means the firm can increase $p_{1}$, since all consumers now recognize those who buy it as the highest types. Those who buy other varieties are now recognized as not having the highest type, which decreases their status. However, the same applies to any consumer who decides to buy nothing, which is the most attractive outside option. Advertising $x_{1}$

\footnotetext{
${ }^{9}$ If all consumers buy some variety, then I must specify out-of-equilibrium beliefs about a consumer who buys nothing. Just as in the previous section, I assume this belief is $\theta_{L}$. These beliefs are only relevant for types $\theta<\theta_{M-1}$, since they are the only ones to receive ads for all varieties. The same point applies below for Proposition 3.
} 
to all consumers therefore decreases their utility but leaves willingness to pay for other varieties unchanged. Non-targeted advertising works by increasing the stigma associated with consumers' outside option, whether or not anybody actually takes that outside option in equilibrium.

Stronger still, exploiting status effects can be understood fully in terms of increasing the stigma associated with buying nothing. The proof of the proposition shows that firm profits can be written as the sum of two terms: profits stemming from intrinsic utility and profits stemming from status utility. Profits from status utility can themselves be expressed as a constant, minus a term that is proportional to the average belief about consumers who buy nothing. To maximize profits from status utility, the firm must make beliefs about types who buy nothing as negative as possible.

Proposition 2 also shows that the firm will use some non-targeted advertising for all varieties, even those bought by very low types. It does so despite the fact that these ads make low types more widely recognized and they suffer low social status. This counterintuitive result can again be explained by the firm's attempts to increase the stigma of buying nothing.

Consumers who buy nothing all have type lower than $\theta_{M}$, which is the lowest type to buy any variety. The firm can make beliefs about these consumers as negative as possible by ensuring they are not confused with anybody who buys a variety. It therefore wants consumers to receive ads for as many varieties as possible, so they can infer that those they do not recognize are precisely those who buy nothing.

Non-targeted advertising for low-end varieties can also be understood in terms of unraveling. Once $x_{1}$ is advertised to all consumers, those who buy $x_{2}$ are the highest types that consumers may not recognize. They are willing to pay to differentiate themselves from those who buy lower-end varieties and those who buy nothing. The firm can therefore broadly advertise $x_{2}$ to lower types and increase $p_{2}$ without decreasing the price of any other variety. By repeatedly applying the same logic, the firm will use some non-targeted advertising for all varieties, even the variety bought by the lowest types.

Non-targeted advertising is used to increase the stigma associated with buying nothing, but as a byproduct it also helps differentiate otherwise identical goods. Non-targeted advertising allows consumers to better identify those in different market segments, which effectively transfers status utility from those who buy low-end varieties to those who buy high-end varieties. All consumers value status to the same extent, so this transfer does not affect firm profits. The revenue the firm loses from low-end varieties is exactly offset by the revenue it gains from high-end varieties. The firm's use of non-targeted advertising does increase differentiation between varieties, but that is not the reason why the firm follows this strategy.

The best way to exploit status effects would be to advertise each variety to all consumers, so that everyone can precisely recognize those who buy nothing as $\theta<\theta_{M}$. The firm does not do this, however, if $M \geq 2$, because it faces a trade-off between exploiting status effects and price discrimination.

The firm can only price discriminate between different segments of the mar- 
ket because high types are uninformed about the varieties bought by low types. All consumers rank varieties in the same order. Varieties bought by low types are unambiguously better deals, because the firm must set a low price to convince low types to buy. The only reason high types do not deviate is that they do not receive ads for these lower-end varieties.

If the firm advertised each variety to all consumers, it would lose all ability to price discriminate. In that case, it would prefer to sell a single variety, which would at least allow it to save on advertising costs.

The trade-off between broad advertising to exploit status effects and targeted advertising to allow for price discrimination determines the main features of the equilibrium: non-targeted advertising for each variety, but only to poorer consumers than those who buy. ${ }^{10}$ The following proposition shows that this trade-off also determines the firm's choice of critical values $\theta_{1}, \ldots \theta_{M}$, and hence of quantity sold of each variety, where $q_{j}=\theta_{H}-\sum_{i=1}^{j} q_{i}$. It can even cause the firm to restrict the number of varieties put on the market.

Proposition 3. Define the critical value $\lambda^{\prime}$ as follows:

$$
\lambda^{\prime} \equiv \frac{2\left(\theta_{H}-\theta_{L}\right)-2 \theta_{L} N}{3\left(\theta_{H}-\theta_{L}\right)-2 \theta_{L} N} \leq \frac{2}{3} .
$$

If $\lambda<\lambda^{\prime}$, then the firm puts $M=N$ varieties on the market, with $\sum_{i=1}^{N} q_{i}<$ $\theta_{H}-\theta_{L}$. Quantity sold is the same for each variety, and is increasing in $\lambda$ :

$$
q=\frac{2 \theta_{H}-\lambda\left(\theta_{H}+\theta_{L}\right)}{2 N+2-\lambda(N+3)}
$$

If $\lambda^{\prime} \leq \lambda<2 / 3$, then the firm puts $M=N$ varieties on the market and sells to all consumers, $\sum_{i=1}^{N} q_{i}=\theta_{H}-\theta_{L}$. Quantity sold for each variety is $q=\left(\theta_{H}-\theta_{L}\right) / N$.

If $2 / 3 \leq \lambda$, then the firm puts $M=1$ variety on the market, and sells to all consumers. Quantity sold is $q=\theta_{H}-\theta_{L}$.

When concern for status is sufficiently high, the equilibrium is dramatically different than the baseline case. Instead of selling a positive amount of all $N$ varieties, the firm prefers to sell only a single one.

The relationship between quantity sold of each variety and concern for status is also discontinuous. When $\lambda<2 / 3$, the firm sells a strictly positive amount of all $N$ varieties, and each quantity is weakly increasing in $\lambda$. But as soon as $\lambda$ exceeds $2 / 3$, quantity sold jumps to zero for all varieties except one. This result stems from how quantity sold relates to the firm's trade-off between status effects and price discrimination.

Profits from intrinsic utility are highest when the firm plays the same strategy as in the baseline case. Profits from status utility are highest when consumers have negative beliefs about those who buy nothing. This amounts to

\footnotetext{
${ }^{10}$ The proof does not make use of the fact that consumer type is uniformly distributed, and so the result holds for a general distribution of types.
} 
consumers believing that those they do not recognize have low type. A consumer who buys $x_{j}$ can recognize all varieties bought by higher types, and knows those he does not recognize have type below $\theta_{j}$. If quantity sold increases for each variety, then $\theta_{j}$ becomes smaller and this consumer can recognize more types. His beliefs about those he doesn't recognize then becomes more negative.

Profits from intrinsic utility are proportional to $1-\lambda$, and those from status utility are proportional to $\lambda$. When $\lambda$ is small, the firm can strike a balance between status effects and price discrimination by still selling $N$ varieties, but with quantity sold slightly higher than in the baseline case. As $\lambda$ increases, the firm increases the quantity sold of each variety. It still price discriminates between $N$ segments of the market, but the equilibrium outcome becomes increasingly different from the baseline.

When $\lambda$ reaches $\lambda^{\prime}$, quantity sold has increased to such an extent that all consumers buy some variety, $\sum_{i=1}^{N} q_{i}=\theta_{H}-\theta_{L}$. The firm is unable to increase quantity sold if $\lambda$ increases still further, because there is simply nobody left to buy. It continues to play the same strategy, but becomes more tempted to forsake all price discrimination and just maximize profits from status utility. It could do so by selling a single variety to all consumers, so each consumer can recognize what everybody else buys. That is exactly what occurs when $\lambda$ reaches $2 / 3$.

When advertising costs are small, as in this set-up, the result depends on consumers all valuing status to the same extent. Another way for the firm to fully exploit status effects would be to sell all $N$ varieties, but to advertise each variety to all consumers. Because $\lambda$ does not vary with type, the firm would lose all ability to price discriminate, and profits would be the same as from selling a single variety. Selling $N$ varieties is suboptimal because it involves strictly more advertising.

If instead $\lambda$ was increasing with type, the firm could advertise $N$ to all consumers and still engage in price discrimination. In this case, high types would be willing to pay more for status than low types. By setting the appropriate prices, the firm could ensure that different types rank varieties in different orders. It could then fully exploit status effect by advertising each variety to all consumers, and still price discriminate between different market segments.

However, this strategy still involves $N$ times more advertising than selling a single variety. Taking explicit account of the cost of advertising should therefore restore the result that the firm sells a single variety.

The only comparable result in the literature is Rayo (2005). He also looks at a monopolist selling multiple varieties to consumers who want to signal their type. An important difference is that consumers are fully informed of all varieties, so that advertising plays no role. Social status depends only on the average type to buy, and willingness to pay for status is increasing in type. In equilibrium, each consumer's best outside option is therefore to buy the variety bought by a slightly lower type.

In this setting, the monopolist may want to restrict the number of varieties on the market and force different types to pool on the same variety. Pooling will reduce profits from these types, but increase profits from slightly higher types 
who want to avoid the pool's low status. For a given distribution of types, the second effect outweighs the first if willingness to pay for status is sufficiently convex in type.

Though there are some similarities in the set-up, the mechanism in the current paper is very different. Here, the firm restricts the number of varieties so that it can inform all consumers about what others buy, and fully exploit status effects, at the lowest possible advertising cost. It will only do so if willingness to pay for status is similar across types, which is the opposite conclusion reached by Rayo. If the firm does restrict the number of varieties, then it will pool all consumers onto a single one. In contrast, pooling is local in Rayo's setting and never involves the highest type, because there would be no higher types outside of the pool to increase profits.

\section{Welfare}

I first examine how individual consumers are affected by sale of the status good. That is, I compare the equilibrium utility of different types to what it would be if the firm could not sell the status good. There are no externalities in the baseline case, so allowing the firm to sell would leave all consumers weakly better off. If any types are now worse off, then it must be because of status effects.

Proposition 4. All types who buy nothing would have higher utility if the firm did not sell the status good. For each variety $x_{j}$, a strictly positive mass of consumers who buy $x_{j}$ would also have higher utility if the firm did not sell the status good. If $\lambda>2 / 3$, then this applies to all consumers.

Selling the status good makes poor consumers who buy nothing worse off. This is a direct consequence of status externalities. If the firm did not sell the status good, then beliefs about all consumers would equal the prior, $\left(\theta_{H}+\theta_{L}\right) / 2$. Selling the status good reveals all those who buy nothing as having below average type, since all $\theta \geq \theta_{M}$ buy some variety. These consumers are left worse off, because some of their social status has been transferred to wealthier consumers.

At the same time, some types who buy each variety are also left worse off, even some who buy high-end varieties. The reason is not that these consumers suffer from low social status. To the contrary, consumers who buy $x_{1}$ are now revealed as having the highest types. The reason is that the stigma now associated with buying nothing pushes these consumers to pay a high price. Beliefs about those who buy nothing are more negative than the prior, and the firm sets the price of each variety to make the lowest type to buy indifferent with buying nothing. For each variety, there are therefore some consumers who are willing to buy, but who would be better off if nobody did.

It can be that some consumers are also left better off by the firm selling the status good, though that is not always the case. When $\lambda>2 / 3$, so the firm sells only one variety, all consumers are actually left worse off. In that case, both the weight consumers place on social status and the stigma associated with buying 
nothing are quite large. It is large enough to convince even the lowest type to buy, at a price which leaves even the highest type worse off.

I now turn to social welfare, defined in terms of total surplus. The explicit cost of advertising is zero and status is a zero-sum game, which implies total surplus is just equal to the intrinsic utility enjoyed by all consumers. Total surplus is strictly increasing in quantity sold, and I consider whether imposing restrictions on advertising can increase total surplus above the equilibrium level. For tractability, I assume the firm can only sell one variety.

If the social planner could choose both price and advertising, then he would clearly advertise and sell the status good to all consumers. A more interesting situation is when the firm retains control over the price. Through possible restrictions on advertising, the social planner can then encourage the firm to expand output.

I consider two possible restrictions on advertising. The first restriction is a ban on non-targeted advertising, so that the firm could only advertise to consumers who will buy the good. The second restriction is a general tax on the volume of advertising.

Proposition 5. Let $N=1$, and suppose $\lambda<\lambda^{\prime}$ from (9) so that $q<\theta_{H}-\theta_{L}$.

Say there was a ban on non-targeted advertising. Then compared to Proposition 1, this ban decreases $p$, and increases both $q$ and total surplus.

Say there was a tax on advertising, so that informing a mass $m$ of consumers cost $\mathrm{cm}$, with $c>0$. Then there exists a threshold value such that, for $c$ below this threshold, the results are identical to Proposition 1. For c above this threshold, the firm only uses targeted advertising, and the tax decreases both $q$ and total surplus.

A ban on non-targeted advertising increases total surplus by providing the firm with an incentive to increase quantity sold. In the presence of status effects, the firm would like to inform as many consumers as possible about the variety it sells. In Proposition 1, the firm restricts sales to consumers with sufficiently high willingness to pay, and informs all others through non-targeted advertising. A ban on non-targeted advertising prevents the firm from doing so. Now, the only way to inform more consumers is to charge a lower price and expand output.

A ban on non-targeted advertising may be difficult to implement, as it would force policy makers to differentiate between different forms of ads. An alternative would be to put in place a tax that is proportional to the total volume of advertising. Such a tax can convince the firm to only use targeted advertising, but the proposition shows that it would be counterproductive.

A linear tax which is sufficiently small will not affect the firm's strategy. The firm will continue to use non-targeted advertising and set the same price as in Proposition 1. If the tax is sufficiently high, then the firm will switch to only targeted advertising. The problem is that under targeted advertising, the firm must increase advertising expenditures to increase quantity sold. A high tax therefore leads the firm to reduce output. The proof shows that any tax large enough to make the firm choose targeted advertising will lead to lower quantity 
sold than in Proposition 1, and so lower social welfare. The problem is that the tax does not differentiate between targeted and non-targeted ads. ${ }^{11}$

\section{Conclusion}

This paper shows that consumer status seeking can explain why firms sometimes use non-targeted advertising. Advertising informs consumers about the existence of goods and allows them to buy, but also allows them to recognize goods when bought by others. Non-targeted advertising can promotes conspicuous consumption, not through persuasion, but just by transmitting information that allows consumers to signal through their purchases.

The results show that a monopolist selling multiple varieties will advertise each variety to those who buy, and also to all poorer consumers. Doing so strikes a balance between broad, non-targeted advertising to exploit status effects, and targeted advertising to better price discriminate. If concern for status is sufficiently high, then the firm will sell only a single variety. Doing so allows it to fully exploit status effects at the lowest possible advertising cost.

An interesting avenue for further research would be to explore how the mechanism in this paper relates to comparative advertising, where one firm's ads refer to a rival firm's products. One piece of unfavourable information about a lowend good is that consumers who buy it are poor, so they may lose social status if the good is widely recognized. It would be interesting to see if a rival firm selling a high-end good might use comparative advertising to inform consumers about the low-end good, ensuring it is recognized and thus obtaining a competitive advantage.

\section{Appendix}

Proof of Proposition 1. Consider a candidate equilibrium with given $q$ and $|a|=m \geq q$. By monotonicity of (1), the firm can set $p$ equal to the willingness to pay of the lowest type to buy, $\theta_{0}$. By (3) and (4), utility from buying is

$$
(1-\lambda) \theta_{0}+\lambda\left\{\left(\frac{m}{\theta_{H}-\theta_{L}}\right) \frac{1}{q} \int_{\theta_{L}}^{\theta_{H}} \theta^{\prime} 1_{b_{\theta^{\prime}}=x} d \theta^{\prime}+\left(1-\frac{m}{\theta_{H}-\theta_{L}}\right)\left(\frac{\theta_{H}+\theta_{L}}{2}\right)\right\},
$$

where the term in large brackets is the weighted average of what informed and uninformed consumers believe about the type of someone who buys. Assuming $q<$ $\theta_{H}-\theta_{L}$, by a similar logic the utility from not buying is

$$
\lambda\left\{\left(\frac{m}{\theta_{H}-\theta_{L}}\right)\left(\frac{1}{\theta_{H}-\theta_{L}-q}\right) \int_{\theta_{L}}^{\theta_{H}} \theta^{\prime} 1_{b_{\theta^{\prime}}=\emptyset} d \theta^{\prime}+\left(1-\frac{m}{\theta_{H}-\theta_{L}}\right)\left(\frac{\theta_{H}+\theta_{L}}{2}\right)\right\},
$$

which gives

\footnotetext{
${ }^{11}$ Allowing the social planner to directly choose the level of advertising would also be counterproductive. It would also lead the monopolist to reduce quantity sold.
} 


$$
p=(1-\lambda) \theta_{0}+\lambda\left(\frac{m}{\theta_{H}-\theta_{L}}\right)\left\{\frac{1}{q} \int_{\theta_{L}}^{\theta_{H}} \theta^{\prime} 1_{b_{\theta^{\prime}}=x} d \theta^{\prime}-\left(\frac{1}{\theta_{H}-\theta_{L}-q}\right) \int_{\theta_{L}}^{\theta_{H}} \theta^{\prime} 1_{b_{\theta^{\prime}}=\emptyset} d \theta^{\prime}\right\} .
$$

Given $q$, setting $\theta_{0}=\theta_{H}-q$ maximizes both $\theta_{0}$ and the term in large brackets. The price is then strictly increasing in $m$ so the firm sets $a=\left[\theta_{L}, \theta_{H}\right]$. Simplifying gives

$$
\begin{gathered}
p=(1-\lambda)\left(\theta_{H}-q\right)+\lambda\left(\frac{\theta_{H}-\theta_{L}}{2}\right), \\
\pi=q\left[(1-\lambda)\left(\theta_{H}-q\right)+\lambda\left(\frac{\theta_{H}-\theta_{L}}{2}\right) .\right]
\end{gathered}
$$

Profits are strictly concave in $q$. Taking the first order condition gives

$$
q=\frac{2 \theta_{H}-\lambda\left(\theta_{H}+\theta_{L}\right)}{4(1-\lambda)}
$$

and plugging back into (11) yields

$$
p=\frac{2 \theta_{H}-\lambda\left(\theta_{H}+\theta_{L}\right)}{4} .
$$

This indeed implies $q<\theta_{H}-\theta_{L}$ iff $\lambda<\lambda^{*}$, given by (5):

$$
\lambda<\frac{2 \theta_{H}-4 \theta_{L}}{3 \theta_{H}-5 \theta_{L}}
$$

Say instead $\lambda \geq \lambda^{*}$. Then the first-order condition is never satisfied for any $q<\theta_{H}-\theta_{L}$. For any such $q$, the firm could earn higher profits in another equilibrium where $q$ is marginally higher.

Say the firm chooses $q=\theta_{H}-\theta_{L}$, and let $\mu$ be the out-of-equilibrium belief about a consumer who deviates by buying nothing. The firm can charge price

$$
p=(1-\lambda)\left(\theta_{H}-q\right)+\lambda\left(\frac{\theta_{H}+\theta_{L}}{2}-\mu\right)
$$

evaluated at $q=\theta_{H}-\theta_{L}$. Profits are decreasing in $\mu$. If $\mu=\theta_{L}$, then (13) coincides with (11), which implies profits are increasing in $q$. It is indeed optimal to have $q=\theta_{H}-\theta_{L}$, so

$$
p=(1-\lambda) \theta_{L}+\lambda\left(\frac{\theta_{H}-\theta_{L}}{2}\right) .
$$

If $\mu>\theta_{L}$, then (13) is strictly less than (11) for any $q$. Rather than choosing $q=\theta_{H}-\theta_{L}$, the firm can earn strictly higher profits in another candidate equilibrium where $q=\theta_{H}-\theta_{L}-\epsilon$, for $\epsilon>0$ and small. As $\epsilon$ tends to zero, profits increase and tend to (12) evaluated at $q=\theta_{H}-\theta_{L}$.

Proof of Proposition 2. Consider profits in a candidate equilibrium where the firm sells a strictly positive quantity of $M \leq N$ varieties. Denote the lowest type to buy $x_{k}$ by $\theta_{k}$, and order varieties such that $\theta_{M}<\theta_{M-1}<\ldots<\theta_{1}$. Let $\mu_{j}$ be the average belief about a consumer who buys $x_{j}$, and $\mu_{\text {not }}$ the average belief about a consumer who buys nothing, as given by (2). 
All consumers must rank varieties in the same order. Type $\theta$ obtains utility $(1-$ $\lambda) \theta+\lambda \mu_{j}-p_{j}$ from $x_{j}$. He prefers $x_{j}$ to $x_{k}$ if and only if $\lambda \mu_{j}-p_{j}>\lambda \mu_{k}-p_{k}$, which is independent of $\theta$.

The incentive to buy any variety $x_{j}$ over buying nothing is increasing in type. If $\theta_{0}$ prefers $x_{j}$ to buying nothing, then all types $\theta>\theta_{0}$ do as well, because $(1-\lambda) \theta+$ $\lambda \mu_{j}-p_{j} \geq \lambda \mu_{n o t}$ is easier to satisfy for larger $\theta$.

For each $x_{j}$, there must be some consumer who buys $x_{j}$ who is indifferent with his best outside option. If not, the firm could increase $p_{j}$ by some $\epsilon>0$ and leave quantity sold of each variety unchanged. Consumers who buy $x_{j}$ would still prefer it to their best outside option, and those who buy other varieties now have a lower incentive to switch to $x_{j}$. That outside option is either to buy nothing or to buy another variety.

If any type who buys $x_{j}$ is indifferent with buying nothing, then it must be $\theta_{j}$, because he is the lowest type. Furthermore, there must be at least one variety where this is in fact the case. Otherwise, all consumers would strictly prefer their own variety to buying nothing. The firm could then increase each $p_{j}$ by the same $\epsilon>0$ and again leave quantity sold unchanged, because it would not change the ranking of varieties.

I group the varieties into $C$ categories with $1 \leq C \leq M$. In each category, I place all the varieties about which consumers are indifferent. Let $N_{k}$ be the number of varieties in category $k$, and denote these varieties by $x_{k 1}, \ldots, x_{k N_{k}}$. Let $\theta_{k i}$ be the lowest type to buy $x_{k i}$, for $1 \leq i \leq N_{k}$. I order varieties so that $\theta_{k N_{k}}<\ldots<\theta_{k 1}$, so the lowest type to buy a variety from category $k$ is $\theta_{k N_{k}}$. I order the categories so that $\theta_{k N_{k}}<\ldots<\theta_{1 N_{1}}$, so the lowest type to buy any variety at all is $\theta_{C N_{C}}$.

Type $\theta_{k N_{k}}$, the lowest type to buy from category $k$, must be indifferent between variety $x_{k N_{k}}$ and buying nothing. If $\theta_{k N_{k}}$ was not indifferent, then any other type $\theta$ who buys from category $k$ would also strictly prefer his variety to buying nothing, since $\theta>\theta_{k N_{k}}$. The firm could increase the price of each variety in category $k$ by the same $\epsilon>0$ and leave quantity sold unchanged. All consumers who buy from category $k$ would remain indifferent between these varieties, and none would want to switch to a different category or to buy nothing. Consumers who buy from other categories would now have less of an incentive to switch to category $k$, so the firm would not be forced to decrease any of its other prices.

Consumers strictly prefer all varieties in category $k$ to all varieties in category $j$ whenever $j<k$. The lowest types to buy from these categories are $\theta_{k N_{k}}$ and $\theta_{j N_{j}}$ with $\theta_{k N_{k}}<\theta_{j N_{j}}$. Both types are indifferent with buying nothing, but higher types have a greater incentive to buy any variety. That means $\theta_{j N_{j}}$ strictly prefers varieties in category $k$ to those in category $j$, and all consumers have the same ranking. In particular, this implies that the firm cannot advertise any variety in category $k$ to consumers who buy from category $j$, for any $j<k$. The consumers, having received the ad, would then prefer to switch.

By definition, consumers are indifferent between varieties in each category. That implies, for any $x_{k i}$ in category $k$, the difference in price between $x_{k i}$ and $x_{k N_{k}}$ must equal the difference in status utility between the two varieties:

$$
p_{k i}-p_{k N_{k}}=\lambda \mu_{k i}-\lambda \mu_{k N_{k}} .
$$

Total profits from all varieties in category $k$ are $\pi_{k}=\sum_{i=1}^{N_{k}} p_{k i} q_{k i}$. Using (14) gives

$$
\pi_{k}=\sum_{i=1}^{N_{k}}\left[p_{k N_{k}}+\lambda\left(\mu_{k i}-\mu_{k N_{k}}\right)\right] q_{k i} .
$$

The price of variety $x_{k N_{k}}$ makes type $\theta_{k N_{k}}$ indifferent with buying nothing: 


$$
p_{k N_{k}}=(1-\lambda) \theta_{k N_{k}}+\lambda\left(\mu_{k N_{k}}-\mu_{n o t}\right) .
$$

Substituting (15) into $\pi_{k}$ and simplifying gives

$$
\pi_{k}=\sum_{i=1}^{N_{k}}\left[(1-\lambda) \theta_{k N_{k}}+\lambda\left(\mu_{\mu_{k i}}-\mu_{n o t}\right)\right] q_{k i} .
$$

Define $Q_{k} \equiv \sum_{i=1}^{N_{k}} q_{k i}$, the total mass of consumers who buy varieties in category $k$. Then total profits from all categories equal

$$
\pi=(1-\lambda) \sum_{k=1}^{C} \theta_{k N_{k}} Q_{k}+\lambda \sum_{j=1}^{M}\left(\mu_{j}-\mu_{n o t}\right) q_{j} .
$$

The first summation gives profits from intrinsic utility, which depend on the quantity sold in each category and the lowest type to buy from each category. The second summation gives profits from status utility, which depend on the beliefs about consumers who buy each variety compared to the beliefs about consumers who buy nothing. The status incentive to buy $x_{j}$ is $\lambda\left(\mu_{j}-\mu_{n o t}\right)$.

In equilibrium, the average of all beliefs, taken over all consumers, must equal the prior:

$$
\sum_{j=1}^{M}\left(\frac{q_{j}}{\theta_{H}-\theta_{L}}\right) \mu_{j}+\left(1-\frac{\sum_{j=1}^{M} q_{j}}{\theta_{H}-\theta_{L}}\right) \mu_{n o t}=\frac{\theta_{H}+\theta_{L}}{2} .
$$

Rearranging and substituting means that equilibrium profits can be written as

$$
(1-\lambda) \sum_{k=1}^{C} \theta_{k N_{k}} Q_{k}+\lambda\left(\theta_{H}-\theta_{L}\right)\left(\frac{\theta_{H}+\theta_{L}}{2}-\mu_{n o t}\right) .
$$

Keep the order of categories fixed, as well as the quantity sold of each category, $Q_{C}, \ldots, Q_{1}$. Profits from the intrinsic utility, given by the first summation in (17) are maximized if the firm sets $\theta_{k N_{k}}=\theta_{H}-\sum_{j=1}^{k} Q_{k}$. For each category, all types who buy a variety from that category would then lie on a single interval. Having multiple disjoint intervals of types buying from the same category would strictly decrease $\theta_{k N_{k}}$ for some $k$ without increasing it for any other $k$.

Profits from status utility are also maximized by setting $\theta_{k N_{k}}=\theta_{H}-\sum_{j=1}^{k} Q_{k}$, and advertising each variety in category $k$ to all $\theta<\theta_{k-1 N_{k-1}}$. Each consumer is then informed about the varieties bought by as many consumers as possible: someone who buys from category $k$ receives ads for all varieties in categories $1, \ldots, k$, bought by $\sum_{i=1}^{k} Q_{k}$ consumers. Moreover, all of these consumers he now recognizes have type over a threshold, namely $\theta_{k N_{k}}$. Together, this makes the average type that each consumer does not recognize as low as possible. By (4), it makes his belief about those he does not recognize as low as possible, and therefore minimizes $\mu_{\text {not }}$. That implies a candidate equilibria of this form gives the highest profits.

I now argue there can be only one variety per category. Say there were multiple varieties in category $k$. From above, all varieties in category $k$ are advertised to the same consumers. Compare profits from another candidate equilibrium where all varieties in category $k$ are replaced by a single variety. The lowest type to buy from any category remains the same, so profits from intrinsic utility in (17) are unchanged. The set of types that each consumer recognizes also remains the same, so $\mu_{n o t}$ is also 
unchanged. Profits according to (17) remain the same, but the firm now uses strictly less advertising.

Proof of Proposition 3. Using (17) and the fact that there is one variety per category, profits are

$$
\pi=(1-\lambda) \sum_{j=1}^{N} q_{j}\left(\theta_{H}-\sum_{i=1}^{j} q_{i}\right)+\lambda\left(\theta_{H}-\theta_{L}\right)\left(\frac{\theta_{H}+\theta_{L}}{2}-\mu_{n o t}\right),
$$

where I have set $N=M$, but the firm can always choose to $q_{j}=0$ for any variety $x_{j}$. The first order condition is

$$
\frac{\partial \pi}{\partial q_{j}}=(1-\lambda)\left(\theta_{H}-\sum_{i=1}^{N} q_{i}-q_{j}\right)-\lambda\left(\theta_{H}-\theta_{L}\right) \frac{\partial \mu_{n o t}}{\partial q_{j}}=0 .
$$

As before, $\mu_{\text {not }}$ is the average belief about consumers who buy nothing, which is the weighted average of the beliefs taken over all consumers about those they don't recognize:

$\mu_{\text {not }}=\sum_{i=1}^{N-1}\left(\frac{q_{i}}{\theta_{H}-\theta_{L}}\right)\left(\frac{\theta_{L}+\theta_{H}-\sum_{j=1}^{i} q_{j}}{2}\right)+\left[1-\sum_{i=1}^{N-1} \frac{q_{i}}{\theta_{H}-\theta_{L}}\right]\left(\frac{\theta_{L}+\theta_{H}-\sum_{j=1}^{N} q_{j}}{2}\right)$.

By Proposition 2, a consumer who buys $x_{i}$ receives ads for all $x_{j}$ with $j \leq i$. Those he does not recognize are uniformly distributed on $\left[\theta_{L}, \theta_{H}-\sum_{j=1}^{i} q_{j}\right]$. The term in square brackets in (19) is the combined mass of consumers who buy $x_{N}$ and those who buy nothing. They all receive ads for each variety, so they hold the same beliefs. Rearranging and differentiating gives

$$
\frac{\partial \mu_{n o t}}{\partial q_{j}}=\frac{1}{2\left(\theta_{H}-\theta_{L}\right)}\left(\sum_{i=1}^{N} q_{i}-q_{j}\right)-\frac{1}{2} .
$$

Plugging into the first order condition gives

$$
\frac{\partial \pi}{\partial q_{j}}=(1-\lambda)\left(\theta_{H}-\sum_{i=1}^{N} q_{i}-q_{j}\right)-\lambda\left(\theta_{H}-\theta_{L}\right)\left\{\frac{1}{2\left(\theta_{H}-\theta_{L}\right)}\left(\sum_{i=1}^{N} q_{i}-q_{j}\right)-\frac{1}{2}\right\}=0 .
$$

These are $N$ linear equations in $N$ unknowns. By symmetry, the solution is $q_{j}=Q$, $j=1, \ldots, N$, given by $(10)$ :

$$
Q=\frac{2 \theta_{H}-\lambda\left(\theta_{H}+\theta_{L}\right)}{2 N+2-\lambda(N+3)}
$$

The solution is indeed interior if $N Q<\theta_{H}-\theta_{L}$. Rearranging shows this is equivalent to $\lambda<\lambda^{\prime}$, as given by (9):

$$
\lambda<\frac{2\left(\theta_{H}-\theta_{L}\right)-2 \theta_{L} N}{3\left(\theta_{H}-\theta_{L}\right)-2 \theta_{L} N},
$$

where $\lambda^{\prime} \leq 2 / 3$. To check the second order condition, we have 


$$
\frac{\partial^{2} \pi}{\partial q_{j}^{2}}=-2(1-\lambda), \quad \frac{\partial^{2} \pi}{\partial q_{i} \partial q_{j}}=\frac{\lambda}{2}-1, i \neq j .
$$

The Hessian has two eigenvalues: $\left(\frac{3+N}{2}\right) \lambda-(N+1)$ and $(3 \lambda-2) / 2$. It is negative definite for $\lambda<2 / 3$. Since $\lambda^{\prime} \leq 2 / 3$, the above solution is indeed the optimum for $\lambda<\lambda^{\prime}$. Taking the derivative of $Q$ gives

$$
\frac{d Q}{d \lambda}=\frac{-\left(\theta_{H}+\theta_{L}\right)[2 N+2-\lambda(N+3)]+(N+3)\left[2 \theta_{H}-\lambda\left(\theta_{H}+\theta_{L}\right)\right]}{[2 N+2-\lambda(N+3)]^{2}} .
$$

Canceling terms, the derivative is positive if $2\left(\theta_{H}-\theta_{L}\right)-2 \theta_{L} N+2 \theta_{H}>0$, which holds because $\lambda<\lambda^{\prime}$.

If $\lambda \geq \lambda^{\prime}$, then we must have a corner solution with $\sum_{i=1}^{N} q_{i}=\theta_{H}-\theta_{L}$. Substituting $q_{N}=\theta_{H}-\theta_{L}-\sum_{i=1}^{N-1} q_{i}$ into (18) and (19) gives

$$
\begin{gathered}
\pi=(1-\lambda)\left\{\sum_{j=1}^{N-1} q_{j}\left(\theta_{H}-\sum_{i=1}^{j} q_{i}\right)+\theta_{L}\left(\theta_{H}-\theta_{L}-\sum_{j=1}^{N-1} q_{i}\right)\right\}+\lambda\left(\theta_{H}-\theta_{L}\right)\left(\frac{\theta_{H}+\theta_{L}}{2}-\mu_{n o t}\right), \\
\mu_{n o t}=\sum_{i=1}^{N-1}\left(\frac{q_{i}}{\theta_{H}-\theta_{L}}\right)\left(\frac{\theta_{H}-\theta_{L}-\sum_{j=1}^{i} q_{j}}{2}\right)+\theta_{L},
\end{gathered}
$$

where I have assumed that types who buy $x_{N}$ hold out-of-equilibrium beliefs $\theta_{L}$ about someone who buys nothing. The first order condition is now

$$
\frac{\partial \pi}{\partial q_{j}}=(1-\lambda)\left(\theta_{H}-\theta_{L}-\sum_{i=1}^{N-1} q_{i}-q_{j}\right)-\lambda\left(\theta_{H}-\theta_{L}\right) \frac{\partial \mu_{n o t}}{\partial q_{j}}=0
$$

where

$$
\frac{\partial \mu_{n o t}}{\partial q_{j}}=\frac{1}{2\left(\theta_{H}-\theta_{L}\right)}\left(\theta_{H}-\theta_{L}-\sum_{i=1}^{N-1} q_{i}-q_{j}\right),
$$

which implies

$$
\frac{\partial \pi}{\partial q_{j}}=(1-\lambda)\left(\theta_{H}-\theta_{L}-\sum_{i=1}^{N-1} q_{i}-q_{j}\right)-\frac{\lambda}{2}\left(\theta_{H}-\theta_{L}-\sum_{i=1}^{N-1} q_{i}-q_{j}\right)=0 .
$$

These are $N-1$ linear equations in $N-1$ unknowns. By symmetry, the solution is $q_{j}=\left(\theta_{H}-\theta_{L}\right) / N, j=1, \ldots, N-1$. Using $\sum_{i=1}^{N} q_{N}=\theta_{H}-\theta_{L}$ gives $q_{N}=\left(\theta_{H}-\theta_{L}\right) / N$.

For the second order condition, we have

$$
\frac{\partial^{2} \pi}{\partial q_{j}^{2}}=3 \lambda-2, \quad \frac{\partial^{2} \pi}{\partial q_{i} \partial q_{j}}=\frac{3 \lambda-2}{2}, i \neq j
$$

The Hessian has two eigenvalues: $(N+1)\left(\frac{3 \lambda-2}{2}\right)$ and $(3 \lambda-2) / 2$. It is negative definite for all $\lambda^{\prime} \leq \lambda<2 / 3$, in which case this is the optimum. The second order condition is violated for $\lambda \geq 2 / 3$, regardless of $N$. The optimal strategy must therefore be a corner solution with $q_{1}=\theta_{H}-\theta_{L}$. 
Proof of Proposition 4. All types $\theta<\theta_{N}$ who buy nothing have utility $\lambda \mu_{n o t}$. By Proposition 2 , the lowest type $\theta_{j}$ who buys variety $x_{j}$ is made indifferent with buying nothing, so he also has utility $\lambda \mu_{n o t}$. If the firm did not sell the status good, then each consumer would just have status utility under the prior, $\lambda\left(\theta_{H}+\theta_{L}\right) / 2$. But (19) implies $\mu_{\text {not }}<\left(\theta_{H}+\theta_{L}\right) / 2$, so that these types all now have lower status utility. By continuity, the same applies for all types $\theta \in\left[\theta_{j}, \theta_{j}+\epsilon\right]$, for $\epsilon>0$ and sufficiently small.

If $\lambda>2 / 3$, then Proposition 3 implies $q=\theta_{H}-\theta_{L}$. The price is given by (8):

$$
p_{1}=(1-\lambda) \theta_{L}+\lambda\left(\frac{\theta_{H}-\theta_{L}}{2}\right) .
$$

Each consumer has the same status utility as under the prior, $\lambda\left(\theta_{H}+\theta_{L}\right) / 2$. The type with the highest intrinsic utility is $\theta_{H}$, with $(1-\lambda) \theta_{H}$. A straightforward comparison shows that $\lambda>2 / 3$ implies $(1-\lambda) \theta_{H}<p_{1}$, so all consumers are left worse off.

Proof of Proposition 5. I use subscript $t$ for equilibrium values with targeted advertising and $n t$ with non-targeted advertising. From Proposition $1, q_{n t}$ is given by (6) and $p_{n t}$ is given by (7). A ban on non-targeted advertising is only relevant in the case of an interior solution, $q_{n t}<\theta_{H}-\theta_{L}$. For that reason, I assume $\lambda<\lambda^{*}$ by (5):

$$
\lambda<\frac{2 \theta_{H}-4 \theta_{L}}{3 \theta_{H}-5 \theta_{L}}
$$

Say there is a ban on non-targeted advertising. For given $q$, the firm can set $p$ similar to (11), except now only a fraction $q /\left(\theta_{H}-\theta_{L}\right)$ of consumers are informed:

$$
\begin{gathered}
p=(1-\lambda)\left(\theta_{H}-q\right)+\lambda\left(\frac{q}{\theta_{H}-\theta_{L}}\right)\left(\frac{\theta_{H}-\theta_{L}}{2}\right), \\
\pi=q\left[(1-\lambda)\left(\theta_{H}-q\right)+\lambda \frac{q}{2}\right] .
\end{gathered}
$$

Taking the first order condition and solving gives

$$
\begin{aligned}
& q_{t}=\frac{(1-\lambda) \theta_{H}}{2-3 \lambda}, \\
& p_{t}=\frac{(1-\lambda) \theta_{H}}{2} .
\end{aligned}
$$

The second order condition is $\lambda<2 / 3$, which holds since $\lambda<\lambda^{*}$. If the above value of $q_{t}$ exceeds $\theta_{H}-\theta_{L}$, then the firm sets $q_{t}=\theta_{H}-\theta_{L}$. In that case, we clearly have $q_{t}>q_{n t}$ because of the assumption $q_{n t}<\theta_{H}-\theta_{L}$. We then have $p_{t}$ as given by (8), and comparing this to (7) gives $p_{t}<p_{n t}$. If $q_{t}<\theta_{H}-\theta_{L}$, then simple algebra shows that $q_{t}>q_{n t}$ iff $\lambda \theta_{H}+(2-3 \lambda) \theta_{L}>0$, and $p_{t}<p_{n t}$ iff $\theta_{H}-\theta_{L}>0$. Both conditions hold since $\lambda<2 / 3$ and $\theta_{H}>\theta_{L}$.

Now consider a tax on advertising, so that informing a mass $m$ of consumers costs $\mathrm{cm}>0$. To sell quantity $q$, the firm can set price

$$
\begin{gathered}
p=(1-\lambda)\left(\theta_{H}-q\right)+\lambda\left(\frac{m}{\theta_{H}-\theta_{L}}\right)\left(\frac{\theta_{H}-\theta_{L}}{2}\right), \\
\pi=q\left[(1-\lambda)\left(\theta_{H}-q\right)+\lambda \frac{m}{2}\right]-c m .
\end{gathered}
$$


The firm must choose $q$ and $m$, subject to the constraint $m \geq q$. Profits are linear in $m$, so the optimum is either $m=\theta_{H}-\theta_{L}$ or $m=q$. If $m=\theta_{H}-\theta_{L}$, then the first order condition with respect to $q$ is

$$
\frac{\partial \pi}{\partial q}=(1-\lambda)\left(\theta_{H}-2 q\right)+\lambda\left(\frac{\theta_{H}-\theta_{L}}{2}\right)=0
$$

This is the same as without a tax, and so implies $q=q_{n t}$ and $q=p_{n t}$. Using (6) and (7), profits are

$$
\pi_{n t}=\frac{1}{16(1-\lambda)}\left[2 \theta_{H}-\lambda\left(\theta_{H}+\theta_{L}\right)\right]^{2}-\left(\theta_{H}-\theta_{L}\right) c .
$$

For $m=q$, the profit function is

$$
\pi=q\left[(1-\lambda)\left(\theta_{H}-q\right)+\lambda \frac{q}{2}-c\right]
$$

The first order condition is

$$
\frac{\partial \pi}{\partial q}=(1-\lambda)\left(\theta_{H}-2 q\right)+\lambda q-c=0
$$

which implies

$$
\begin{aligned}
& q_{t}=\frac{(1-\lambda) \theta_{H}-c}{2-3 \lambda}, \\
& p_{t}=\frac{(1-\lambda) \theta_{H}+c}{2} .
\end{aligned}
$$

For sufficiently large $c$, we have $q_{t}<\theta_{H}-\theta_{L}$. Depending on parameter values, this inequlity may also hold for all $c$. If $q_{t}<\theta_{H}-\theta_{L}$ does hold, then taking into account the cost of advertising, profits are

$$
\pi_{t}=\frac{1}{2(2-3 \lambda)}\left[(1-\lambda) \theta_{H}-c\right]^{2} .
$$

Comparing (23) with (6), we have $q_{t}>q_{n t}$ iff $c<c^{*}$, where

$$
c^{*} \equiv \frac{\lambda}{4(1-\lambda)}\left[\lambda \theta_{H}+(2-3 \lambda) \theta_{L}\right]
$$

Say $q_{t}<\theta_{H}-\theta_{L}$, for all $c$, as given by (23). Then (22) and (24) imply

$$
\pi_{n t}-\pi_{t}=\frac{1}{16(1-\lambda)}\left[(2-\lambda) \theta_{H}-\lambda \theta_{L}\right]^{2}-\left(\theta_{H}-\theta_{L}\right) c-\frac{1}{2(2-3 \lambda)}\left[(1-\lambda) \theta_{H}-c\right]^{2},
$$

which is quadratic in $c$. The firm uses non-targeted advertising iff $\pi_{n t}-\pi_{t}>0$. That is certainly the case when $c=0$, since then non-targeted advertising is optimal by Proposition 1. But the coefficient for $c^{2}$ is negative, which implies $\pi_{n t}-\pi_{t}>0$ iff $c$ is below some strictly positive threshold.

If $c$ is below this threshold, then the firm uses non-targeted advertising and the results are as given in Proposition 1. I now show that $c \leq c^{*}$ implies $\pi_{n t}-\pi_{t}>0$. That is equivalent to $\pi_{n t}-\pi_{t} \leq 0$ implying $c>c^{*}$. So if $c$ is high enough to induce the firm to use targeted advertising, then it is also high enough to make $q_{t}<q_{n t}$. Total surplus just depends on quantity sold, since status is a zero sum game, and so it too will be lower. 
Note that (25) is concave in $c$, so I just need to show that $\pi_{n t}-\pi_{t}>0$ at $c=0$ and at $c=c^{*}$. As noted above, it must be positive at $c=0$. Plugging $c^{*}$ into (25), expanding and regrouping terms yields

$$
\pi_{n t}-\pi_{t}=\frac{\lambda}{32(1-\lambda)^{2}}\left[(5 \lambda-4) \theta_{L}-(3 \lambda-2) \theta_{H}\right]^{2},
$$

which is also positive.

Now say (23) exceeds $\theta_{H}-\theta_{L}$ for some small values of $c$. That is, there exists $c^{\prime}<c^{*}$ such that $c<c^{\prime}$ implies $q_{n t}=\theta_{H}-\theta_{L}$. Then for all $c<c^{\prime}, m=\theta_{H}-\theta_{L}$ under both targeted and non-targeted advertising, and $\pi_{n t}-\pi_{t}$ does not depend on $c$. That means $\pi_{n t}-\pi_{t}$ is still concave in $c$, and $\pi_{n t}-\pi_{t}>0$ for all $c \leq c^{*}$.

\section{References}

Aaker, D. (1996). Building Strong Brands. New York: The Free Press.

Bagwell, K. and G. Ramey (1994, January). Advertising and coordination. Review of Economic Studies 61(1), 153-72.

Bagwell, L. S. and B. D. Bernheim (1996, June). Veblen effects in a theory of conspicuous consumption. American Economic Review 86(3), 349-73.

Becker, G. S. and K. M. Murphy (1993, November). A simple theory of advertising as a good or bad. The Quarterly Journal of Economics 108(4), 941-64.

Belk, R. W. (1988, September). Possessions and the extended self. Journal of Consumer Research: An Interdisciplinary Quarterly 15(2), 139-68.

Bernheim, B. D. (1994, October). A theory of conformity. Journal of Political Economy 102(5), 841-77.

Butters, G. R. (1977). Equilibrium distributions of sales and advertising prices. The Review of Economic Studies 44(3), 465-491.

Cho, I.-K. and D. M. Kreps (1987, May). Signaling games and stable equilibria. The Quarterly Journal of Economics 102(2), 179-221.

Chwe, M. S.-Y. (2001). Rational Ritual: Culture, Coordination, and Common Knowledge. Princeton: Princeton University Press.

Dixit, A. and V. Norman (1978). Advertising and welfare. The Bell Journal of Economics 9(1), 1-17.

Englis, B. G. and M. R. Solomon (1995, Spring). To be and not to be: Lifestyle imagery, reference groups, and the clustering of America. Journal of Advertising $24(1), 13-28$.

Esteban, L., A. Gil, and J. M. Hernandez (2001, June). Informative advertising and optimal targeting in a monopoly. Journal of Industrial Economics 49(2), $161-80$.

Esteban, L., J. M. Hernandez, and J. L. Moraga-Gonzalez (2006, March). Customer directed advertising and product quality. Journal of Economic $\mathcal{E}$ Management Strategy 15(4), 943-68.

Fehr, E. and K. M. Schmidt (1999, August). A theory of fairness, competition, and cooperation. The Quarterly Journal of Economics 114(3), 817-868.

Frank, R. H. (1985, March). The demand for unobservable and other nonpositional goods. American Economic Review 75(1), 101-16. 
Grossman, G. M. and C. Shapiro (1984, January). Informative advertising with differentiated products. Review of Economic Studies 51(1), 63-81.

Hernandez-Garcia, J. M. (1997, August). Informative advertising, imperfect targeting and welfare. Economics Letters 55(1), 131-137.

Ireland, N. J. (1994, January). On limiting the market for status signals. Journal of Public Economics 53(1), 91-110.

Johnson, J. P. (2009). Targeted advertising and advertising avoidance. Mimeo, Johnson Graduate School of Management, Cornell University.

Kapferer, J. and V. Bastien (2009). The Luxury Strategy: Break the Rules of Marketing to Build Luxury Brands. London: Kogan Page.

Kapferer, J.-N. (2008). The New Strategic Brand Management. Kogan Page.

Kihlstrom, R. E. and M. H. Riordan (1984, June). Advertising as a signal. Journal of Political Economy 92(3), 427-50.

Kotler, P. and K. L. Keller (2008). Marketing Management (13th Edition). Prentice Hall.

Krahmer, D. (2006, December). Advertising and conspicuous consumption. Journal of Institutional and Theoretical Economics (JITE) 162(4), 661-682.

Levy, S. J. (1959, July-August). Symbols for sale. Harvard Business Review 37(4), $117-24$.

Levy, S. J. (1963). Symbolism and lifestyle. Proceedings, American Marketing Association Conference, 140-50.

McAfee, R. P. and M. Schwartz (1994). Opportunism in multilateral vertical contracting: Nondiscrimination, exclusivity, and uniformity. The American Economic Review 84(1), pp. 210-230.

Meurer, M. and D. I. Stahl (1994, March). Informative advertising and product match. International Journal of Industrial Organization 12(1), 1-19.

Milgrom, P. and J. Roberts (1986, August). Price and advertising signals of product quality. Journal of Political Economy 94(4), 796-821.

Miller, G. (2009). Spent: Sex, Evolution, and the Secrets of Consumerism. London: Random House.

Nelson, P. (1974, July/Aug.). Advertising as information. Journal of Political Economy 82(4), 729-54.

Pastine, I. and T. Pastine (2002, August). Comsumption externalities, coordination, and advertising. International Economic Review 43(3), 919-943.

Rayo, L. (2005). Monopolistic signal provision. B.E. Journal of Theoretical Economics.

Rey, P. and T. Verg (2004). Bilateral control with vertical contracts. The RAND Journal of Economics 35(4), pp. 728-746.

Stigler, G. J. and G. S. Becker (1977, March). De gustibus non est disputandum. American Economic Review 67(2), 76-90.

Swinkels, J. M. and L. Samuelson (2006, March). Information, evolution and utility. Theoretical Economics 1(1), 119-142.

Veblen, T. (1899). The Theory of the Leisure Class. Penguin Classics.

Wernerfelt, B. (1990, January). Advertising content when brand choice is a signal. Journal of Business 63(1), 91-98. 